'PHILOSOPHICAL INTER VIEWS'

\title{
Interview with Shahid Rahman
}

\author{
By Diogo Silva da Cunha ${ }^{1}$
}

Philosophical Inter Views is an internal project of the Science-Art-Philosophy Lab of the Centre for the Philosophy of Sciences of the University of Lisbon (CFCUL). Scientific Coordinators: Catarina Pombo Nabais (CFCUL) catarinapombonabais@ gmail.com; Diogo Silva da Cunha (CFCUL) cunhadiogo15@gmail.com; João Pinheiro (CFCUL) joaopinheiro@hotmail.com.

Project's homepage: http://cfcul.fc.ul.pt/projectos/philosophical-inter-views/index.php

Diogo Silva da Cunha (Centro de Filosofia das Ciências da Universidade de Lisboa) cunhadiogo15@gmail.com

DOI 10.1515/kjps-2016-0005

Shahid Rahman is professor for Logic and Epistemology at the University Charles-de-Gaulle, Lille 3, where he is responsible for the Masters and Doctorate specializations in the same area. He is also responsible for the domain "Concepts et pratiques philosophiques" of the Unité Mixte de Recherche 8163 "Savoirs, Textes, Langage" and, together with John Symons, he is Chief-Editor of the Springer series on "Logic, Epistemology, and the Unity of Science". Professor Rahman's work deals mainly with logical inferences in the context of History and Philosophy of Science. He visited the Centre for Philosophy of Sciences of the University of Lisbon between the 27th and 29th of October, 2015. On the first day

1 I would like to thank Klaus Gärtner for his time and sympathy but mostly for his insightful revisions of this text. 
of his stay, he gave a lecture entitled "Interaction and the Genealogy of Identity" in the context of the Permanent Seminar in Philosophy of Sciences. On the second day, Shahid Rahman meet with PhD students and Postdoctoral fellows in an informal setting. He used this time to listen to their research projects and make some suggestions. On the third day, he gave a second lecture with the title "On the Possible" opening the thematic Seminar series of the Graduate Program in Philosophy of Science, Technology, Art and Society. The text that follows is the transcription of an interview recorded at the Faculty of Sciences of the University of Lisbon after a very interesting lunch on the 28 th of October.

Diogo Silva da Cunha (DSC): You are one of the Chief-Editors of the Springer series on "Logic, Epistemology, and the Unity of Science" since it was first published. You and John Symons signed the opening text for the series, where both of you distinguished between 'science unity' and 'science unification'. What do mean by this distinction?

Shahid Rahman (SR): Let us get to the story. There was already a project about the unity of science conducted by the Vienna Circle. There was even an editorial project: The International Encyclopedia of Unified Science. Over time, the project became a reductionist program. The idea was that unity of science means unifying sciences in the reductionist sense. That was also a late upshot of logicism and other projects of this sort. However, the Vienna Circle's project failed due to many reasons. As a result, general skepticism was imposed in Philosophy of Science, arguing that there is no such thing as unity of science. This idea was justified by three interconnected reasons: unity was assumed to be a reduction, reduction was understood in a logical sense, and logic had too many shortcomings. This idea of skepticism lead to some extreme views, according to which, all Philosophy of Science was reduced to a kind of Sociology of Science. It is undeniable that what we learned from the sociological and historical perspectives is very important. However, John and I still have the view that it [unity of science] makes sense in our days. Today, one should at least discuss it. Of course, this means that the reductionist problem cannot be avoided: how is it possible to speak of the unity of science without falling into reductionism? I have called this view 'dynamical unity in diversity', and we formulated it like that, in 
the preface of the first volume. It states that science can produce knowledge without losing its identity. It is a not a reductionist program, it is a pluralist one. This means that 'unity' is not understood as unification or, at least, that unification is not understood as reduction.

DSC: In the same text you and Symons claimed that a consequence of this distinction is that "any work of unification contributes to the thesis of unity; though factors of unity will not be able to offer arguments in favour of unification". If I'm not wrong, this means that factors, such as objects and methods, are not able to offer arguments in favour of unification.

SR: Yes. That was what we have learned after [Thomas] Kuhn. There are no absolutely theoretical independent facts. The only thing one can do is to establish theoretical links between different facts. To put it in a different way, the role of facts is to foster cross-fertility. It is similar to the act of stealing. When you steal an object, you transform it. That is, you take someone else's facts, transform them, and turn them into your own. Perhaps you misinterpret them, but it won't matter because this kind of transformation can still have a positive heuristic. This is the fruitful side of establishing theoretical links. Thinking that there is a fact that will produce unification is a kind of reductionist assumption. I ought to say, however, that the preface was written in 2001. It was 15 years ago. In some respect, we have changed our view, or at least I did.

DSC: In which respects did you change?

SR: We mentioned something that was not pondered enough. I'm taking this into account in the edition of new books. I'm referring to the reasons sustaining the skepticism regarding the unity of science and, more generally, regarding a certain notion of knowledge. What I mean is that the concept of knowledge in traditional Philosophy of Science depends on the separation between context of discovery and context of justification. Actually, that was the diagnosis we gave in those days. But knowledge is something else. Now I think that history should have been stressed more. I think three components are important: the production of knowledge in its different aspects, the role of knowledge, and the diachronic and synchronic study of knowledge.

DSC: Despite the fact that you and your colleagues state that the preponderance of unified scientific theories might not be ignored, you refer 
to the devastating evidence of disunity of the sciences without giving any examples. In your opinion, what kind of arguments of the disunity thesis should one really take into account?

SR: Let me tell you a bit about the background of that. When we came up with the project of developing this series, most of the big authors of those days were against it. After Kuhn and [Paul] Feyerabend it was easy to argue against the idea of unity of science. This was the case in the majority of the sciences. There are concrete examples for that. Every physicist would tell you that the problem is that there is no unified theory. Even in Mathematics and Logic itself, it was and still is very difficult to find a unified theory. In Logic it is like in the jungle. Everyday there is something new. In Biology it is not even clear what is going on... We acknowledged that our project was the classical one. Nevertheless, we thought that the project was possible and necessary, at least to create a place to revisit those apparently old issues. My reaction was simple. I wrote to the most important philosophers of science of those days, such as [Hilary] Putnam, [Saul] Kripke, Bas van Fraassen, and [Timothy] Williamson among others, and they all wrote back saying they loved the project. All of them also wanted to revisit these issues, and many of them accepted to be on the Editorial Board. So, at least they liked the idea to open those issues for discussion again.

DSC: Moreover, you and your colleagues point out that there are relevant misinterpretations about the idea of the unity of science, particularly about the notion that unity of science is incompatible with methodological and ontological diversity. In your view the contrary is the case. You talk about the relationship between genetics and evolutionary theory, as an example. In your view, how can this relationship enlighten our idea of diversity in the context of the unity of science?

SR: I'm not a specialist in Philosophy of Biology. That part is much more John's than mine. But I think I can illuminate this view. If I remember well what we wrote, the idea was that, even if different approaches seem create disunity, they could interact. One could take parts from the other and make it one's own. That was the simple idea. Especially because of big discussion in Biology about how Neo-Darwinism should be interpreted. We thought that, even if there are different paradigms, there is something like a 'family resemblance', if you want to put it in [Ludwig] 
Wittgenstein terms. That was the philosophical background. What means unity? In this sense, unity has to do with the fact that, despite that one can say that there are different things sharing different proprieties, this is not the same as to say that there is a property that everything shares.

DSC: Does that mean that there is no such thing as a universal property?

SR: Yes. But perhaps I will put it in another way: at least, you do not need to have such an assumption. To have a universal property is not a necessary assumption. But it is important to say that John Symons and I have a very different philosophical point of view. John defends naturalized epistemology. I am not. I am a constructivist. Over the years, both of us started to defend more extreme positions. By now, I am by far a more radical constructivist.

DSC: Further misreadings you pointed out can be related with your constructivist view. You have argued that unification does not mean applying a single set of laws to distinct fields. Do you mean that scientific laws are discipline-specific?

SR: This is really my idea, yes. It is behind my constructivist view. It is easier to see it the other way around. When I talk about a finite set of general laws, I'm thinking in axiomatization. Now, it is evident, with the exception of, I would say, trivial parts of sciences, that most of the fragments of sciences or entire sciences cannot be axiomatized. Even Mathematics cannot be completely axiomatized. Not even elementary Arithmetic can be completely axiomatized. This happens already in Biology. In the Social Sciences it would be hopeless. What would one say? That Social Sciences are not sciences at all? That would be ridiculous! What I really thought in those days, was that each science has its own architectonic. That is something that [Henri] Poincaré takes from [Immanuel] Kant. Architectonic means conceptual links. That is, for me, what really makes a science the science it is. A science is made by its conceptual links, the links it has, it develops and it creates. Let me rephrase it. First, there is no way of axiomatization in general. Axiomatization is very useful for some fragments but most of the sciences cannot be axiomatized. Second, I defend that instead of a general axiomatization there is an architecture of each science. Third, I would add a reasoning 
practice associated with this architecture, a reasoning practice proper to each science. What is behind this sentence is that each science might have its own logic. The logics are different.

DSC: In which sense do you use the term 'logic' in this context?

SR: 'Logic', here, stands for 'inference', to the possibility of the activity of inferring. Not only in the sense usually identified in logic, not only in the syntactic derivation of logic. Let me give you some examples of what I mean by the word 'inference'. Given some materiality, if you say something is red, you are inferring that it is of such color. In the traditional way of defining logic, that won't be an inference because that wouldn't be valid. But this inference stems from the meaning. Logic has an expressive power associated with the sense of the word 'meaning'. It has the expressive power of meaning.

DSC: In the lecture you gave yesterday, you said that 'logic' is not a matter of 'representation' but of 'expression'. That follows from a Kantian tradition. That was something that Charles Sanders Peirce had already claimed, understanding 'logic' as 'inference'. But there are other ways to grasp 'representation'.

SR: Yes, that is right. The notion of representation that I am denying is the one introduced by David Hume, which was the spawn of a certain interpretation of Ludwig Wittgenstein's Tractatus Logico-Philosophicus. I am talking about the nice book by Richard Rorty entitled Philosophy and the Mirror of Nature. Well, it is against this type of representation that I am arguing. I think Kant's idea of representation is, as you said, in the way of what I mean with the expression. The novelty of representation is in Kant. It has a normative aspect, a creative aspect. To put it in another way, representation is understood as creation or as reflection. When we represent, what are we reflecting on? That is certainly the difference between construction and description. What for a descriptionist, such as Symons, are regularities, for a constructivist like me are norms. Now, take one particular science as an example. There are some practices specific to that science at various levels: inferentional practices, verification practices, experimentation practices, and so on. When do we have knowledge? One way to put it is the following way: when you have a proposition, when you express the links of that sci- 
ence with propositions. Today this orientation is called 'intellectualism' by a lot of people. It is often claimed that it does not presuppose any practical knowledge at all. Even for a scientist, however, this would be very strange. Stated explicitly, it would mean that in the practice of a science you would need a philosopher or a logician to produce knowledge. This is why we need to explain this practice, where knowledge is not explicitly structured and described in this sense. There are two ways of doing so. One way is to describe regularities: you ascribe knowledge because there are some behavioral regularities and in other cases you don't. So, you have regularities and non-regularities or irregularities. Also, from a learning perspective, there are behavioral regularities and irregularities. Knowledge stems from what is sometimes called 'bundle of regularities'. Then there is a second position, a more extreme one. It states that some behavioral regularities are wrong. What is claimed here, is that practical knowledge is not only linked to some conducts, but that it is also linked to the possibility of stating that those conducts are wrong. How do you do that? You confront someone else with a certain behavior - that is where I locate 'interaction' - and ask for the reasons of that behavior. That is how you take responsibility for your acts. This the normative dimension in a Kantian sense. If you want to do it this way, you have to do two things: you have to give the reasons for it, and you also have to entitle someone else to use these reasons for himself. One essential component underlying the unity of science is interaction. I think that knowledge is intimately related to interaction.

DSC: Let us go back to where we started. In the text opening the series on "Logic, Epistemology, and the Unity of Science" you talked about interdisciplinary and communication in the senses you've used until now - as cross-fertilization and as interaction - but you clearly avoided the term incommensurability and all the problems it poses to these issues.

SR: We didn't talk about that because in the first place this project was anti-Kuhnian. Nevertheless, I think that the problem of incommensurability is not settled, it is not very clear. Even conceding that there might be such thing as incommensurability, until now I didn't find any convincing examples of it in the history of science. Most of the historians of science find counter-examples in specific cases of incommensurability. They conclude that the examples are not perfect but that they can help 
to highlight some idea of incommensurability. It looks like incommensurability settles that the gap created by the change from one paradigm to the other - if there is something as drastic as that - is linked to the development of a series of debates that take place at a specific time. I prefer to think that meaning is constituted by those debates. I really think that the claim is something that [Gaston] Bachelard already pointed out and Marcelo Dascal worked so much for. It is the importance of debates. It is in the evolution of those debates that incommensurability should be thought, because there is a change of meaning that happens during those debates. It seems that the main example of a paradigm change is the one of [Nicolaus] Copernicus. However, even this one is bound to fail. What Kuhn treated as the best example of his paradigm shift is the result of an historical misinterpretation. There is a paper written by Hassan Tahiri in which he shows that the so-called "Copernican revolution" case is an evolution of the debates that happened in the Arabic Tradition with Ibn al-Haytham. There is an entire treatise of Ibn al-Haytham that was forgotten! So, the best example of a paradigm shift is a mistake resulting from disregarding the Arabic Tradition. Because the History of Science forgot this tradition, it looks like there was a gap. The paper of Tahiri was a really big deal. It was discussed in the University of Cambridge, for example. I would say that, if we learned from Kuhn that the History of Science is something much more important than philosophers thought, this also applies to himself.

DSC: From that point of view can we say that the disunity critiques of the first project of the unity of science - the accusation of the lack of practical and sociohistorical understanding of sciences by the philosophers - is also a problem shared with historians of science?

SR: Yes, that is precisely what I am saying. That is something I should have stressed more, right from the start of the project: the real importance of history.

DSC: But how can one reflect about epistemological and especially logical issues and take into account those practical and socio-historical aspects without falling into different kinds of relativism?

SR: It is true that there is a kind of relativism, but that is not purely historical. That is why we wanted to go for unity. In the days we began 
our series, for me, the ways to avoid relativism weren't as clearer as today. Today I would say that it is the role of logic. Again, not of logic as producing a reduction, but a kind of interactional logic or, if you want, a kind of 'trans-subjective objective' logic or something like that. There is an acknowledgement of the logics of interaction. This means that logic for me is not a logic. For me, logic is a frame of rational interaction. How do you avoid relativism? That is what I said before, you avoid it by taking responsibility for your actions, you have to say why you did something. Certainly these inferences have to be connected to all the inferences that are being taken under consideration in a scientific community. When you introduce a new term, you have to look whether or not it is compatible with all the inferences of the scientific community. In some cases, it could produce something new. But there is - although this is not a nice expression - a conservative extension. That is to say that the new meaning introduced, even though new, should not alter totally the other established meanings. If not, anything would go. When you say "I will introduce a new concept", someone asks you "Why?" and then you answer with the inference of the new concept and the reasons explaining its necessity. But this might affect other concepts. The problem is how to coordinate them. So, it is a problem of conceptual coordination.

DSC: Well, you are still advocating for the unity of science through logics. But one has to take under consideration that the disrepute of the project of 'unity of science' was, at least to some extent, a result of the disrepute of logical analysis.

SR: Yes and no. That is precisely the central question. Yes, but only one kind of logical analysis...

DSC: The classical one...

SR: Yes, the classical logical analysis. The logic being used came to explain one question: "What is a mathematical proof?" It is not surprising that it doesn't apply to everything. It is not the fault of [Gottlob] Frege, but of the people who want to apply it. Frege had only one question in mind but he was very German and made a very lengthy answer with three books. His question was: "Why is mathematics universally applicable?" And his answer was: "Because it is logic". Logic is taken as universal by definition, or at least its truth is taken to be universal by definition. Every 
philosopher would stop there. But he didn't. First, he developed the logic that he meant to be the universal one, which he did in his first book, the Begriffsschrift. Second, he wrote another book, the Grundgesetze der Arithmetik, in which he shows how the concept of number is reducible to logical terms. And, third, he tried to show that this failed, and how all Mathematics can be axiomatized by logic. So, in fact, all the Logic that we have is the logic, which was thought to respond to a singular question, that of mathematical proof. It was not Frege's fault that his project derived from a particular question. He created what in some sense is Philosophy of Mathematics. Later, however, people - especially [Alfred] Tarski and his school in the United States - started to use Frege's ideas for natural languages. And, then it was spread. Still, there is, and I think I still adhere to, a very radical idea of Frege: there is no other way to access to knowledge - he would probably say to thought - than through the logical analysis. He is saying that that's the only way to access them. He develops a method that is very good for understanding mathematical concepts. But it is not enough, not even for Mathematics. We cannot reduce each science to that kind of analysis. But since then there was a huge development of logics. By now, there are so many logics that you cannot even put all of them together and philosophers of science discuss Philosophy of Science as if those logics didn't exist. We have at our disposal a lot of logics with different motivations: some from Economy, others from Sociology, and so on and so forth. Nevertheless, Philosophy of Science didn't incorporate them! One of the challenges today is that. That is why logic is so important.

DSC: Over the last years you have been one of those, worldwide responsible, for the development of dialogical logic. If there are so many logics, what is the place of this one?

SR: When Mathematics became the paradigm of reasoning - which happened after Frege - one of the things that disappeared was the link between logic and argumentation, but argumentation was the origin of logics! The origin of logics was how arguments take place, what is a valid argument, and to argue was to interact. This was lost because calculus is "monologic", if you want. In the 1950 s, one important influence and a very intelligent man called [Charles] Perelman defended the idea that logic and argumentation have to be separated. Something similar was 
claimed by Stephen Toulmin. They took the other horn of the dilemma and they had very good reasons. I, however, deeply disagree with the consequences of their positions. The main claim of Perelman's idea was that we should have - and that is a nice idea, I think he was better than his followers - a new paradigm of normative reasoning. He found it in Law. Perelman says that natural and rational argumentation needs 'Law' as a paradigm. I understand what he's pointing out there. He is pointing out that interaction is very important and that it can be lost with pure calculus. In general, argumentation theorists gave up too quickly. They said "Well, it is not possible. There is no reduction. There is not just one logic. Well, forget logic". Then they created something called 'practical argumentative schemes'. For example, in the Belgium School Perelman's followers claim that argumentation is about empathy, there is no validity or correctness. For them, the main target of argumentation is to create empathy with the listener. For me, problems identical to the ones of regularities that l've already talked about follow. Now, going back again. In 1958, Perelman didn't realize that Paul Lorenzen and Kuno Lorenz, who was my professor, developed dialogical logic, recovering the argumentative roots of logic and its interaction aspects, also using Game Theory. But they were reductionists. I mean, they thought that dialogical logic was the only logic. Now, I think that that is not true. Dialogical logic is not even a logic. It is a frame or a conception of logic. Let us look to what axiomatic means. Axiomatic is not a logic, it is a method for doing inferences or deriving, but there are a lot of axiomatics. In a similar way, dialogical logic is not a logic, but a framework. From this framework, I developed more than 40 or 60 logics in collaboration with different groups. The place of dialogical logic is to recover two lost links: the social component of reasoning, interaction, and its epistemic character, the constitution of knowledge. That is our place in logic. When you are not mainstream the first thing everyone wants to know is if you can do the same thing they can do with their logics. I spent 20 years of my life showing that I can. This was the main motivation behind the paper on dialogical logic for the Stanford Encyclopedia, by Laurent Keiff, an ex-student of mine. But when you show you can, like I did, the answer is that: if they already have it, they won't need yours. Fair enough, what they want to know now is what is new in this conception of logic. Now, 
after 20 years of work showing what is similar, I am showing what is different, what we can do that they can't. In some things we are better, in some things we are not. It is very easy for us to represent interaction, it is more natural, it is not represented in a static but in a dynamic way. Moreover, our framework allows us to understand logic as developing patterns for the cooperative enterprise of rationality. Our difficulty is that, since it is richer, it is more complex. One example is that we distinguish more levels. For us, a scientist does not win a debate independently of the context. This means that we distinguish more levels than the one of 'winning'. We see that a scientist wins because of the context. These level distinctions are precisely why our task is so difficult. 